\title{
How do treatment aims in the last phase of life relate to hospitalizations and hospital mortality? A mortality follow-back study of Dutch patients with five types of cancer
}

\author{
Mariska Oosterveld-Vlug ${ }^{1}$ • Gé Donker ${ }^{2} \cdot$ Femke Atsma $^{3}$ • Linda Brom ${ }^{4}$. \\ Yvonne de $\mathrm{Man}^{3} \cdot$ Stef Groenewoud ${ }^{3}$ - Bregje Onwuteaka-Philipsen ${ }^{1}$
}

Received: 3 April 2017 / Accepted: 11 September 2017 /Published online: 22 September 2017

(C) The Author(s) 2017. This article is an open access publication

\begin{abstract}
Purpose The purpose of this study is to describe and compare the relation between treatment aims, hospitalizations, and hospital mortality for Dutch patients who died from lung, colorectal, breast, prostate, or pancreatic cancer.

Methods A mortality follow-back study was conducted within a sentinel network of Dutch general practitioners (GPs), who recorded the end-of-life care of 691 patients who died from one of the abovementioned cancer types between 2009 and 2015. Differences in care by type of cancer were analyzed using multilevel analyses to control for clustering within general practices.

Results Among all cancer types, patients with prostate cancer most often and patients with pancreatic cancer least often had a palliative treatment aim a month before death $(95 \%$ resp. $84 \%$ ). Prostate cancer patients were also least often admitted to hospital in the last month of life (18.5\%) and least often died there $(3.1 \%)$, whereas lung cancer patients were at the other end of the spectrum with $41.8 \%$ of them being admitted to hospital and $22.6 \%$ dying in hospital. Having a palliative
\end{abstract}

Mariska Oosterveld-Vlug

m.oosterveld@vumc.nl; eol@vumc.nl

1 Department of Public and Occupational Health, Amsterdam Public Health research institute, Expertise Center for Palliative Care, VU University Medical Center, Van der Boechorststraat 7, 1081 BT Amsterdam, The Netherlands

2 NIVEL, Netherlands Institute of Health Services Research, Utrecht, The Netherlands

3 Scientific Institute for Quality of Healthcare, Radboud University Medical Center, Nijmegen, The Netherlands

4 IKNL, Netherlands Comprehensive Cancer Organization, Utrecht, The Netherlands treatment aim and being older were significantly associated with less hospital admissions, and having a palliative treatment aim, having prostate cancer, and dying in a more recent year were significantly associated with less hospital deaths.

Conclusion There is large variation between patients with different cancer types with regard to treatment aims, hospital admissions, and hospital deaths. The results highlight the need for early initiation of GP palliative care to support patients from all cancer types to stay at the place they prefer as long as possible.

Keywords Palliative care $\cdot$ Treatment aim $\cdot$ Cancer . Hospitalization $\cdot$ Hospital mortality $\cdot$ End-of-life care

\section{Introduction}

At the end of life, the majority of people prefer to be cared for and die at home [1,2]. An international study in Belgium, the Netherlands, Italy, and Spain found that $71-90 \%$ of the cancer patients whose preferred place of death was known by their GP wanted to die at home, against only $1-6 \%$ in hospital [3]. Accordingly, a low percentage of hospitalizations and a high percentage of patients who die at home are being regarded as indicators of high-quality palliative care $[4,5]$. To achieve this, the availability of community-based palliative care is very important in order to support patients' wishes and care needs. The Netherlands is one of the countries that have a generalist palliative care model $[6,7]$, meaning that for patients at home, GPs are central to the coordination and provision of care at the end of life, together with a community nurse, when needed. The GP remains the treating physician in the palliative and dying phase and can 
consult a specialist or specialized palliative team in complex cases [8].

One of the most important aspects of GP palliative care is the timely recognition of palliative care needs. There is evidence that having a palliative treatment goal, i.e., a treatment aimed at maximizing a patient's comfort, leads to favorable outcomes. Abarshi et al. (2010) found that patients whose care in the last phase of life was primarily palliative were less likely to be transferred between care settings and less likely to die in hospital [9]. Many studies point out that cancer patients receive more palliative care and in an earlier stage than non-cancer patients [10-13]. Cancer patients are also more involved in end-of-life discussions and advance care planning than, for example, patients with dementia or organ failure [14]. These differences are often attributed to cancer patients' more predictable illness trajectories [10, 14-16].

However, even for the patient group with the most predictable illness trajectory, GPs seem to face difficulties combining disease management and palliative approaches. A study by Claessen et al. (2013) revealed that the main impetus for Dutch GPs to initiate a palliative approach with cancer patients is information from the medical specialist stating that curative treatments are no longer available, and that not all GPs see added value in discussing palliative care with the patient when cure is still an option [17]. Moreover, the cancer patient population is not a homogeneous one, as different types of cancer vary widely in incidence and possibilities for treatment and cure. As a result, 5-year survival rates vary considerably: from 88 and $87 \%$ for prostate and breast cancer patients to 17 and even only $7 \%$ for patients with lung and pancreatic cancer [18]. Thus, although the typical illness trajectories for progressive chronic illnesses show that patients with cancer experience rapid decline in the terminal phase $[19,20]$, the speed and length of the period of functional decline might differ by cancer type as well as by age and gender [21]. These factors could all have consequences for the timely initiation of palliative care.

Until now, no studies have examined aspects of GP end-oflife care by cancer type. For the five most common cancer types causing death in the Netherlands-lung, colorectal, breast, prostate, and pancreatic cancer, together accounting for more than 58\% of Dutch cancer decedents [22] - this study aims to (1) describe and compare the aims of treatment during the last week of life, 2 to 4 weeks before death, and 2 to 3 months before death, (2) describe and compare the percentage of patients who were admitted to hospital within the last month of life and died in hospital, and (3) examine which patient characteristics and treatment aims relate to hospital admissions and hospital mortality.

\section{Methods}

\section{Study design}

This paper is based on data from the Dutch SentiMELC (Sentinel network Monitoring End-of-Life Care) study, a retrospective mortality follow-back study monitoring the quality of end-of-life patient care through continuous GP registration. Since 2005, data on demographic, health, and care characteristics for all deaths of practice patients is collected via a sentinel network of GPs in the Netherlands. This network, consisting on average of 58 regularly participating GP practices, covers $0.7 \%$ of the total registered patient population [23] and is coordinated by NIVEL, the Netherlands Institute of Health Services Research. It is designed and managed to be nationally representative (with regard to age, gender, geographic distribution, and population density). Next to endof-life patient care, GPs continuously report on all cases of particular conditions and interventions, in order to study disease prevalence and associated factors [23]. According to Dutch law, the SentiMELC study is exempt from ethical approval, since posthumous collection of anonymous patient data is allowed in the Netherlands [24].

\section{Measurement instrument and procedure}

Within a week after a patient's death, participating GPs were asked to report on the care this patient had received in the last 3 months of life. The standardized questionnaire included, among others, structured questions on patient characteristics: age, gender, main place of residence in the last year of life, main diagnosis, and place of death. Also, characteristics of care were collected, such as the number of hospital admissions and the goal of treatment within three time periods before death. GPs were asked to rate on a five-point Likert scale the extent to which they thought that cure, life prolongation, and comfort/palliation had been important $(1=$ totally unimportant, 5 = very important) during the patients' last week of life, 2 to 4 weeks before death, and 2 to 3 months before death. As the importance of each treatment aim was rated separately for each time period, multiple aims were possible within the same time period. Completed questionnaires (in printed form until 2014, electronically from 2015 on) were returned to NIVEL, where they were scrutinized for missing data and errors before they were sent to the researchers for analyses. In case the questionnaire contained a lot of missing or incorrect data, the GPs were contacted to provide additional information.

\section{Study population}

For this paper, we analyzed data from 2009 to 2015. In these 7 years, Dutch Sentinel GPs recorded the deaths of 3365 patients, of which 1318 (39.2\%) had a main diagnosis of cancer. 
More than half of these cancer patients were diagnosed with lung, colorectal, breast, prostate, or pancreatic cancer $(N=716,53.4 \%)$. We only selected those patients who were under their GP's care in the last year of life, as determined from the patient's main place of residence in the last year of life (home or residential care home) $(N=691)$. Nursing home residents, cared for by an elderly-care physician, were excluded, as were patients whose main residence was "other" or "unknown."

\section{Data analysis}

Descriptive statistics were used to describe patient and care characteristics by cancer type. To control for clustering of observations within general practices, differences in characteristics were assessed using generalized linear mixed models reporting $p$ value for malignancy site as a fixed effect. Then, we dichotomized the five response options for each treatment aim and each time period by separating response options four "important" and five "very important" (collectively referred to as "important") from response options 1 to 3 and analyzed the importance of each treatment aim at different time periods by cancer type. Subsequently, we examined which combination of treatment aims and patient characteristics relate to being admitted to hospital (at least once versus no hospital admission in the last month of life) and dying in the hospital (yes versus no). We therefore combined the treatment aims "cure" and "life prolongation" and created the new variables "cure/life prolongation as sole important treatment aim," "both palliation and cure/life prolongation as important treatment aims," "palliation as sole important treatment aim," and "no treatment aim important." These variables were all entered into a backward multivariable logistic regression model using generalized linear mixed models. We removed the independent variables stepwise until all $p$ values were below 0.05 and calculated the odds ratios. Analyses were carried out in SPSS 20.

\section{Results}

\section{Characteristics of study population}

Of the 691 deceased cancer patients, 297 had lung cancer (43.0\%), 183 colorectal cancer $(26.5 \%), 80$ breast cancer (11.6\%), 65 prostate cancer $(9.4 \%)$, and 66 pancreatic cancer $(9.6 \%)$ (Table 1). Gender, age, and place of death differed significantly by cancer type. The youngest decedents were patients with a main diagnosis of lung cancer (mean 70.1 years), while, on average, prostate cancer patients died 8 years older (mean 78.1 years). The majority of patients died at home, but there was substantial variation in the percentage of home deaths (e.g., $55.5 \%$ of colorectal cancer patients versus $72.3 \%$ of prostate cancer patients) as well as in the percentage of patients who died in hospital $(3.1 \%$ of prostate cancer patients up to $22.6 \%$ of lung cancer patients). This variation was also reflected - although not significant - in the number of hospital admissions in the last 30 days of life, with prostate cancer patients being least (18.5\%) and lung cancer patients being most often admitted (41.8\%).

\section{Treatment aims in the last 3 months of life}

Figure 1 depicts the proportion of patients per cancer type with a certain treatment aim. For all cancer types, the proportion of patients with a palliative treatment aim increased, whereas the importance of curative and life-prolonging treatment aims decreased closer to death. The variation between cancer types with regard to the proportion of patients with a certain treatment aim was larger at 3 to 2 months before death than in the last week of life (Fig. 1). For example, whereas the importance of a palliative treatment aim initially ranged from $72 \%$ (pancreatic cancer) to $84 \%$ (colorectal cancer), this range narrowed to $91 \%$ (pancreatic cancer) to $96 \%$ (prostate cancer) in the last week of life. Similar narrowing patterns were found for the variation between cancer types with regard to all other treatment aims.

Furthermore, Fig. 1 shows that patients with prostate cancer most often $(95 \%)$ and patients with pancreatic cancer least often $(84 \%)$ had a palliative treatment aimwhether or not in combination with another aim -in their last month of life. In addition, breast cancer patients more often than patients with other cancer types had a curative or life-prolonging treatment aim until the end of life. However, controlling for differences in age and gender, the importance of treatment aims in different time periods did not differ significantly between cancer types, apart from two findings (analysis shown in Appendix Table 4). First, patients with different cancer types substantially varied with regard to having a life-prolonging treatment aim in the last week of life ranging from $2 \%$ of prostate cancer patients up to $18 \%$ of breast cancer patients. Secondly, compared to lung cancer patients, patients with pancreatic cancer were less likely to receive palliative care in weeks 4 to 2 before death (OR 0.41 ) (see Appendix Table 4).

\section{Factors associated with hospital admissions in the last 30 days of life}

Of the patients with a sole curative/life-prolonging treatment aim in months 3 to 2 before death, $55.3 \%$ were admitted to hospital in the last 30 days of life, whereas this was only $21.1 \%$ for patients with a sole palliative treatment aim (Table 2). The multivariate model shows 


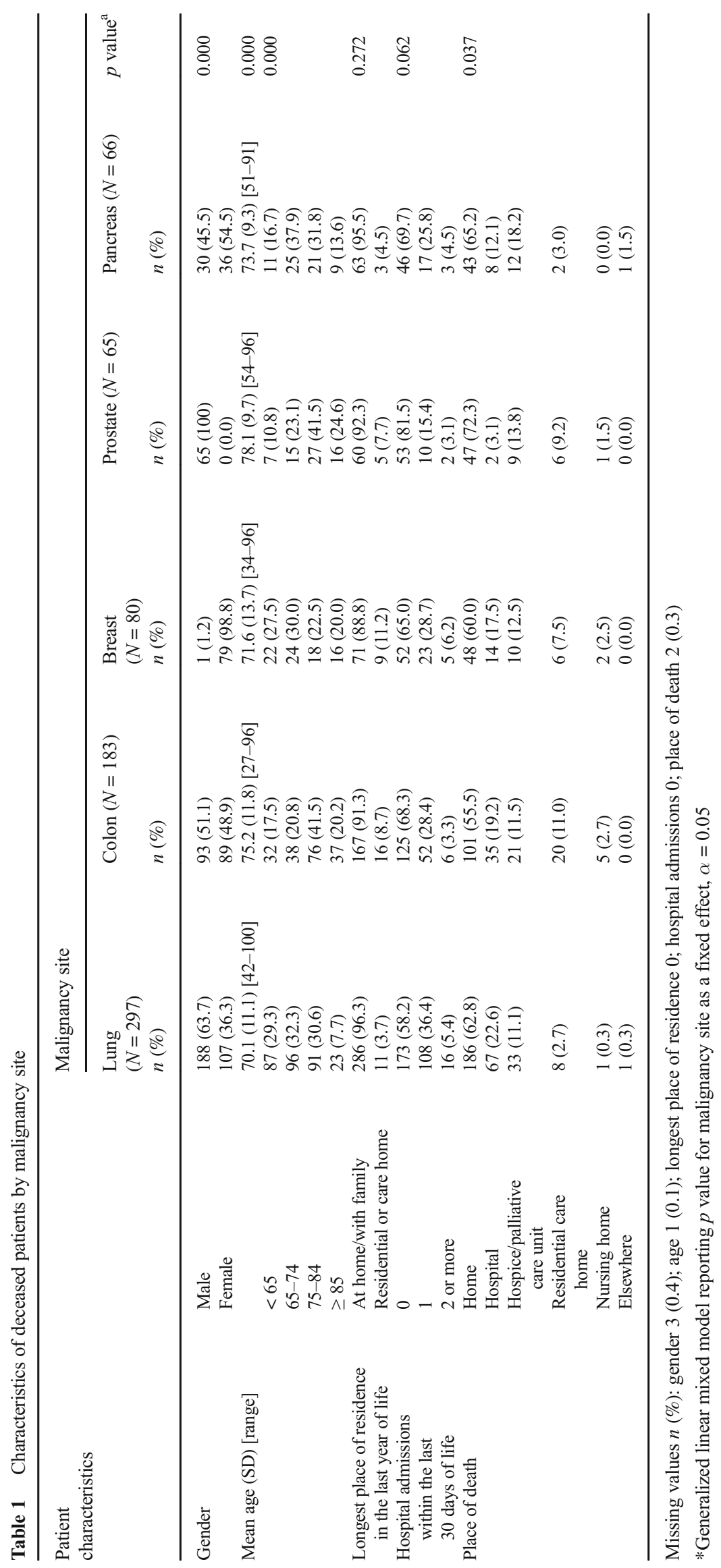


Fig. 1 Importance of treatment aims in three time periods before death
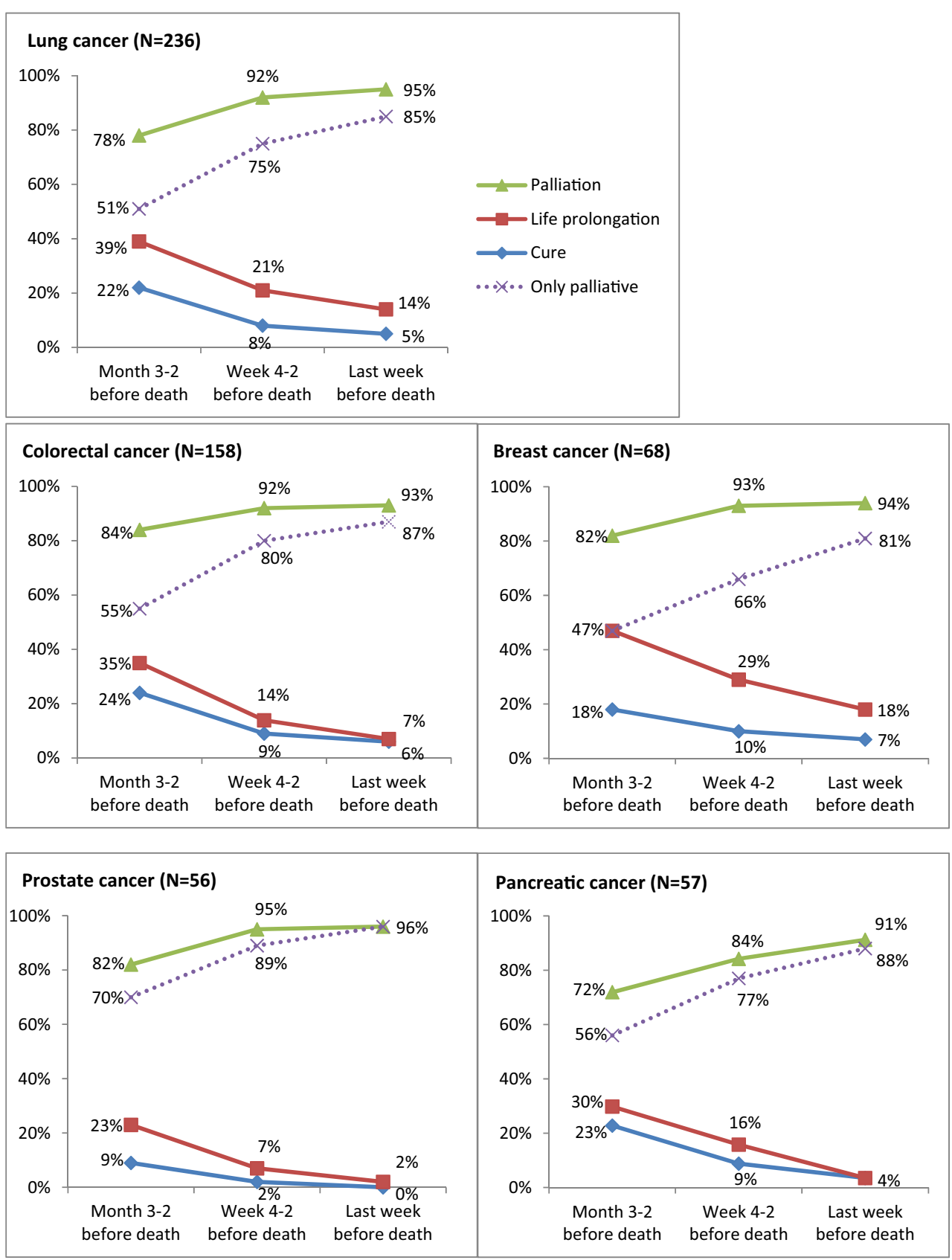

that, compared to patients with a sole palliative treatment aim, the odds of being admitted to hospital was significantly higher for patients with a combined treatment aim (OR 2.58) or sole curative/life-prolonging treatment aim (OR 4.32) at months 3 to 2 before death. In addition, the model shows that older patients were less likely to be hospitalized in the last month of life (OR 0.97) (Table 2).

\section{Factors associated with dying in hospital}

The proportion of patients who died in hospital was lowest among patients with a sole palliative treatment aim (8.0\%) and highest among patients with a sole curative/life-prolonging treatment aim at months 3 to 2 before death $(25.9 \%)$ (Table 3). Correspondingly, the multivariate analysis showed that - compared to patients with a sole palliative treatment aim - the odds of dying in hospital was significantly higher for patients with a combined treatment aim (OR 2.38), sole curative/life-prolonging treatment aim (OR 3.98), or no important treatment aim (OR 3.16) at months 3 to 2 before death. Other factors that were associated with less hospital mortality were having prostate cancer (as compared to having lung cancer, OR 0.27) and dying in a more recent year (OR 0.79) (Table 3). 
Table 2 Associations between treatment aims, patient characteristics, and hospital admissions in the last 30 days of life

\begin{tabular}{|c|c|c|c|c|}
\hline & & $\begin{array}{l}\text { At least } 1 \text { hospital } \\
\text { admission } \\
n(\%)\end{array}$ & $\begin{array}{l}\text { Univariate } \\
\text { OR }(95 \% \mathrm{CI})\end{array}$ & $\begin{array}{l}\text { Multivariate } \\
(N=587) \\
\text { OR }(95 \% \mathrm{CI})\end{array}$ \\
\hline \multirow{4}{*}{$\begin{array}{l}\text { Treatment aim months } \\
3-2 \text { before } \\
\text { death }(n=588)\end{array}$} & Palliative only $(n=313)$ & $66(21.1)$ & 1 & 1 \\
\hline & $\begin{array}{l}\text { Both palliative and curative/ } \\
\text { life-prolonging }(n=159)\end{array}$ & $66(41.5)$ & $2.81(1.81-4.35)^{* * *}$ & $2.58(1.66-4.02)^{* * *}$ \\
\hline & Curative/life-prolonging only $(n=85)$ & $47(55.3)$ & $4.83(2.85-8.18)^{* * *}$ & $4.32(2.53-7.38)^{* * *}$ \\
\hline & No important aim $(n=31)$ & $7(22.6)$ & $1.07(0.43-2.64)$ & $1.13(0.45-2.79)$ \\
\hline \multirow{5}{*}{$\begin{array}{l}\text { Malignancy site } \\
\quad(n=691)\end{array}$} & Lung $(n=297)$ & $124(41.8)$ & 1 & - \\
\hline & Colon $(n=183)$ & $58(31.7)$ & $0.65(0.44-0.96)^{*}$ & - \\
\hline & Breast $(n=80)$ & $28(35.0)$ & $0.77(0.46-1.30)$ & - \\
\hline & Prostate $(n=65)$ & $12(18.5)$ & $0.33(0.17-0.64)^{* *}$ & - \\
\hline & Pancreas $(n=66)$ & $20(30.3)$ & $0.60(0.34-1.08)$ & - \\
\hline Age $(n=690)$ & & & $0.98(0.96-0.99)^{* * *}$ & $0.97(0.96-0.99)^{* *}$ \\
\hline \multirow[t]{2}{*}{ Gender $(n=688)$} & Male $(n=377)$ & $132(35.0)$ & 1 & - \\
\hline & Female $(n=311)$ & $110(35.4)$ & $1.01(0.73-1.38)$ & - \\
\hline \multirow{3}{*}{$\begin{array}{l}\text { Longest place of residence } \\
\qquad(n=691) \\
\text { Year }(n=691)\end{array}$} & Home/with family $(n=647)$ & $233(36.0)$ & 1 & - \\
\hline & Residential or care home $(n=44)$ & $9(20.5)$ & $0.47\left(0.22-1.00^{\mathrm{a}}\right)$ & - \\
\hline & & & $1.08(0.99-1.17)$ & - \\
\hline
\end{tabular}

AUC multivariate model $=0.684$. All variables were entered into the multivariate analysis. Variables that were removed stepwise: (1) longest place of residence, (2) gender, (3) year, and (4) malignancy site

$*$, **, and *** significance at the $p<0.05, p<0.01$, and $p<0.001$ levels, respectively

${ }^{a}$ Value higher than 1.00 at third decimal place

\section{Discussion}

This study revealed large variation with regard to treatment aims, hospital admissions, and hospital mortality (and their interrelatedness) among Dutch patients who died from lung, colorectal, breast, prostate, or pancreatic cancer.
With regard to variation in treatment aims, our study showed that patients with prostate cancer most often and patients with pancreatic cancer least often had a palliative treatment aim in their last month of life. In addition, breast cancer patients more often than all other cancer patients had a curative or life-prolonging treatment aim

Table 3 Associations between treatment aims, patient characteristics, and hospital mortality

\begin{tabular}{|c|c|c|c|c|}
\hline & & $\begin{array}{l}\text { Death in hospital } \\
n(\%)\end{array}$ & $\begin{array}{l}\text { Univariate } \\
\text { OR }(95 \% \mathrm{CI})\end{array}$ & $\begin{array}{l}\text { Multivariate }(n=588) \\
\text { OR }(95 \% \text { CI })\end{array}$ \\
\hline \multirow{4}{*}{$\begin{array}{l}\text { Treatment aim months 3-2 } \\
\text { before death }(n=588)\end{array}$} & Palliative only $(n=313)$ & $25(8.0)$ & 1 & 1 \\
\hline & $\begin{array}{l}\text { Both palliative and curative/ } \\
\text { life prolonging }(n=159)\end{array}$ & $29(18.2)$ & $2.43(1.38-4.28)^{* *}$ & $2.38(1.34-4.23)^{* *}$ \\
\hline & Curative/life prolonging only $(n=85)$ & $22(25.9)$ & $3.81(2.03-7.15)^{* * *}$ & $3.98(2.09-7.57)^{* * *}$ \\
\hline & No important aim $(n=31)$ & $7(22.6)$ & $3.18(1.25-8.09)^{*}$ & $3.16(1.22-8.18)^{*}$ \\
\hline \multirow[t]{5}{*}{ Malignancy site $(n=691)$} & Lung $(n=297)$ & $67(22.6)$ & 1 & 1 \\
\hline & Colon $(n=183)$ & $35(19.2)$ & $0.81(0.51-1.28)$ & $0.83(0.47-1.47)$ \\
\hline & Breast $(n=80)$ & $14(17.5)$ & $0.73(0.38-1.38)$ & $0.97(0.47-2.02)$ \\
\hline & Prostate $(n=65)$ & $2(3.1)$ & $0.17(0.05-0.55)^{* *}$ & $0.27(0.08-0.91)^{*}$ \\
\hline & Pancreas $(n=66)$ & $8(12.1)$ & $0.48(0.22-1.04)$ & $0.39(0.14-1.09)$ \\
\hline Age $(n=690)$ & & & $0.98\left(0.97-1.00^{\mathrm{a}}\right)^{*}$ & - \\
\hline \multirow[t]{2}{*}{ Gender $(n=688)$} & Male $(n=377)$ & $59(15.6)$ & 1 & - \\
\hline & Female $(n=311)$ & $67(21.5)$ & $1.48\left(1.00^{\mathrm{b}}-2.19\right)^{*}$ & - \\
\hline \multirow[t]{2}{*}{$\begin{array}{l}\text { Longest place of residence } \\
\qquad(n=691)\end{array}$} & $\begin{array}{l}\text { Home/with family } \\
\quad(n=647)\end{array}$ & $121(18.7)$ & 1 & - \\
\hline & Residential or care home $(n=44)$ & $5(11.4)$ & $0.56(0.22-1.46)$ & - \\
\hline Year $(n=691)$ & & & $0.87(0.78-0.96)^{* *}$ & $0.79(0.70-0.89)^{* * *}$ \\
\hline
\end{tabular}

AUC multivariate model $=0.657$. Variables entered into the multivariate analysis were significant in the univariate analyses: age, gender, malignancy site, year, and treatment aim months 3-2 before death. Variables that were removed stepwise: (1) age, (2) gender

$*$, **, and *** significance at the $p<0.05, p<0.01$, and $p<0.001$ levels, respectively

${ }^{a}$ Value less than 1.00 at third decimal place

${ }^{\mathrm{b}}$ Value higher than 1.00 at third decimal place 
until the end of life, often combined with a palliative aim as well. It is likely that this variation in treatment aims is related to prognosis and survival. For example, it has been investigated that more than half of pancreatic cancer patients already present with metastatic disease at the time of diagnosis, resulting in a median survival of only 9 to 11 weeks [25] and a 1-year survival rate of only $24 \%$ [18]. Although a diagnosis of pancreatic cancer in itself should thus ideally trigger physicians to start palliative care in practice, some patients with this type of cancer may deteriorate and die so abruptly that it is difficult for both the patient and the physician to find the right moment. In contrast to pancreatic cancer, the 5-year survival rate for breast cancer is remarkably high (87\%) [18], which may contribute to physicians' and patients' tendency to continue with curative or life-prolonging treatments as long as possible. However, we found no indications for such a tendency among patients with prostate cancer, although they have a similar high 5-year survival rate (88\%) [18]. Apparently, not only differences in prognosis may lead to variation in treatment aims between cancer types, but also availability of curative and life-prolonging treatment options, experienced symptom burden, and the patient's age are likely to play a role here. With regard to the latter, the prostate cancer patients in our study were averagely 6.5 years older than those with breast cancer. As earlier studies found that older people are more often treated with a palliative-centered goal [12, 26, 27], our finding that prostate cancer patients most often had a palliative treatment goal may reflect a palliative philosophy in the care of the older old in the Netherlands. However, further qualitative research is recommended to be able to better interpret the variation in treatment aims we found.

Also, with regard to the percentage of patients who were admitted to hospital and died there, considerable variation was found between cancer types, with prostate cancer patients having the lowest rate for hospital admissions in the last month of life (18.5\%) as well as for dying in hospital $(3.1 \%)$ and lung cancer patients having the highest rates for both outcome variables $(41.8 \%$ resp. 22.6\%). These findings are in line with data from Statistics Netherlands [28] and with results from an international comparative study that found a higher percentage of hospital admissions in the last month of life as well as a higher percentage of hospital mortality among patients with lung cancer as compared to the total cancer population [29]. A study on reasons for hospitalization at the end of life found that acute episodes played a role in $70 \%$ of hospitalizations among cancer patients and that respiratory and digestive problems were most common in this patient group [30]. Acute episodes such as shortness of breath, pain, and an altered level of consciousness are indeed common reasons for hospitalization in patients with lung cancer [31] and an important explanation for the fact that lung cancer patients visit the emergency room more often than patients with other types of cancer [32]. Keeping in mind that the frequency of certain acute complications differs by cancer type and that hospitalizations can be beneficial to a patient's quality of life as well (e.g., when receiving a blood transfusion), a study by De Korte-Verhoef et al. (2014) showed that, according to GPs, nearly a quarter of last hospitalizations in the final 3 months of life of cancer patients could have been avoided in retrospect [33]. They most frequently mentioned "proactive communication with the patient, including talking about withholding curative and lifeprolonging treatments and diagnostics" as strategy to avoid hospitalizations. GPs however also stated that it is difficult to find the right moment to discuss such issues, especially with patients who unexpectedly deteriorate quickly or with those who are in a slow deterioration process [33].

This resonates with our finding that having a palliative treatment aim as only important aim and being older were significantly associated with less hospital admissions in the last month of life, and that having a palliative treatment aim as only important aim, having prostate cancer, and dying in a more recent year were associated with less hospital mortality. This is in line with earlier studies on health care transitions in the last phase of life showing that having a palliative treatment goal reduces the risk of being transferred between care settings and of dying in hospital [9], and that curative or life-prolonging treatments were most frequently mentioned as reasons for terminal hospital admissions [34]. The decreasing trend in hospital mortality is also reported elsewhere. In two consecutive measurements, Cohen et al. reported a decreasing trend in hospital mortality in several European countries, among which is the Netherlands. For example, the proportion of Dutch cancer patients dying in hospital decreased from $31 \%$ in 2003 to $26 \%$ in $2008[35,36]$. Other research additionally pointed to prostate cancer as one of the diseases with the strongest decline in hospital mortality over the years [37]. Several factors may explain this decreasing trend; it could be a reflection of more community services being available such as the expansion of home care [38], but also of policy changes with regard to hospital admissions and discharge-e.g., when terminally ill patients are nowadays discharged more early to other external palliative care services [37]. All the same, these results and our findings even more emphasize the need for early initiation of GP palliative care to support patients from all cancer types to receive care and die at their preferred location, which presumably is, according to what has been found in earlier studies [1-3], "at home." 


\section{Methodological considerations}

To the best of our knowledge, this study is the first to directly compare treatment aims, hospital admissions, and hospital mortality by cancer type. Strengths include the use of an established GP network, which is designed to be representative for the Netherlands and in which GPs were not chosen based on a particular interest in end-of-life care. By using a retrospective study design, we were able to get valuable insights with regard to the importance of treatment aims in different time periods before death, which could not have been discerned from administrative health databases. However, the retrospective nature of data collection might have evoked some recall bias. Although this was minimized by weekly registration of deaths, it could be that GPs were inclined to overestimate the importance of palliative treatment aims, being aware now that the patient was in his/her last phase of life. On the other hand, it is also possible that GPs overestimated the importance of curative treatment aims, as the aims of care provided in other settings (e.g., hospitals) were also open to GPs interpretation and medical specialists do not always adequately and timely inform GPs about a curative treatment aim having changed into a palliative one [39]. Furthermore, it is worth noting that for a small portion of cancer patients, none of the three treatment aims (cure, life prolongation, or comfort/palliation) was rated as important at 3 to 2 months before death. Although it is likely that some of them were not diagnosed with cancer yet in this time period, further prospective and qualitative research may help in understanding the situation of these patients as well as why treatment aims and care outcomes like hospitalizations and hospital mortality differ by cancer type.

\section{Conclusion}

There is large variation between different types of cancer with regard to treatment aims, hospital admissions, and hospital mortality. As having a palliative treatment aim is associated with less hospital admissions and less hospital mortality, the results highlight the need for early recognition of the palliative phase and timely initiation of GP palliative care to support patients from all cancer types to stay at the place they prefer as long as possible.

\section{Compliance with ethical standards}

Conflict of interest The authors declare that they have no competing interests.

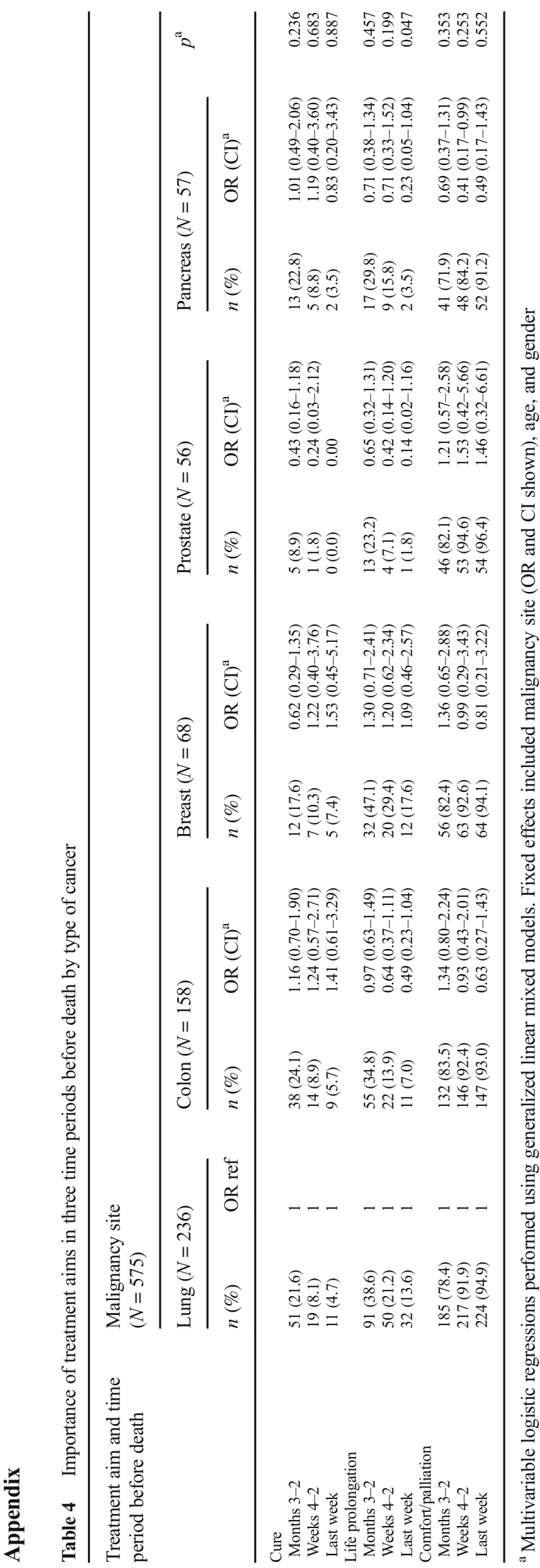




Open Access This article is distributed under the terms of the Creative Commons Attribution-NonCommercial 4.0 International License (http:// creativecommons.org/licenses/by-nc/4.0/), which permits any noncommercial use, distribution, and reproduction in any medium, provided you give appropriate credit to the original author(s) and the source, provide a link to the Creative Commons license, and indicate if changes were made.

\section{References}

1. Higginson IJ, Sen-Gupta GJA (2000) Place of care in advanced cancer: a qualitative systematic review literature review of patient preferences. J Palliat Med 3:287-300. https://doi.org/10.1089/jpm. 2000.3.287

2. Gomes B, Calanzani N, Gysels M, Hall S, Higginson IJ (2013) Heterogeneity and changes in preferences for dying at home: a systematic review. BMC Palliat Care 12:7. https://doi.org/10. 1186/1472-684X-12-7

3. Ko W, Beccaro M, Miccinesi G, Van Casteren V, Donker GA, Onwuteaka-Philipsen B, Miralles Espi MT, Deliens L, Costantini M, Van den Block L (2013) Awareness of general practitioners concerning cancer patients' preferences for place of death: evidence from four European countries. Eur J Cancer 49:1967-1974. https:// doi.org/10.1016/j.ejca.2013.01.006

4. Earle CC, Park ER, Lai B, Weeks JC, Ayanian JZ, Block S (2013) Identifying potential indicators of the quality of end-of-life cancer care from administrative data. J Clin Oncol 21:1133-1138. https:// doi.org/10.1200/JCO.2003.03.059

5. De Roo ML, Miccinesi G, Onwuteaka-Philipsen BD, Van den Noortgate N, Van den Block L, Bonacchi A, Donker GA, Lozano Alonso JE, Moreels S, Deliens L, Francke AL (2014) Actual and preferred place of death of home-dwelling patients in four European countries: making sense of quality indicators. PLoS One 9:e93762. https://doi.org/10.1371/journal.pone.0093762

6. Janssens RJPA, Ten Have HAMJ (2001) The concept of palliative care in the Netherlands. Palliat Med 15:481-486. https://doi.org/10. 1191/026921601682553969

7. Evans N, Costantini M, Pasman HRW, Van den Block L, Donker GA, Miccinesi G, Bertolissi S, Gil M, Boffin N, Zurriaga O, Deliens L, Onwuteaka-Philipsen B (2014a) End-of-life communication: a retrospective survey of representative GP networks in four countries. J Pain Symptom Manag 47:604-619. https://doi.org/10. 1016/j.jpainsymman.2013.04.008

8. Brinkman-Stoppelenburg A, Onwuteaka-Philipsen BD, van der Heide A (2015) Involvement of supportive care professionals in patient care in the last month of life. Support Care Cancer 23: 2899-2906. https://doi.org/10.1007/s00520-015-2655-3

9. Abarshi E, Echteld M, Van den Block L, Donker G, Deliens L, Onwuteaka-Philipsen B (2010a) Transitions between care settings at the end of life in the Netherlands: results from a nationwide study. Palliat Med 24:166-174. https://doi.org/10.1177/ 0269216309351381

10. McKinley RK, Stokes T, Exley C, Field D (2004) Care of people dying with malignant and cardiorespiratory disease in general practice. Br J Gen Pract 54:909-913

11. Beernaert K, Cohen C, Deliens L, Devroey D, Vanthomme K, Pardon K, Van den Block L (2013) Referral to palliative care in COPD and other chronic diseases: a population-based study. Respir Med 107:1731-1739. https://doi.org/10.1016/j.rmed.2013.06.003

12. Pivodic L, Pardon K, Van den Block L, Van Casteren V, Miccinesi G, Donker GA, Alonso TV, Alonso JL, Aprile PL, OnwuteakaPhilipsen DL (2013) Palliative care service use in four European countries: a cross-national retrospective study via representative networks of general practitioners. PLoS One 8:e84440. https://doi. org/10.1371/journal.pone.0084440

13. Evans N, Pasman HRW, Donker GA, Deliens L, Van den Block L, Onwuteaka-Philipsen B (2014b) End-of-life care in general practice: a cross-sectional, retrospective survey of 'cancer', 'organ failure' and 'old-age/dementia' patients. Palliat Med 28:965-975. https://doi.org/10.1177/0269216314526271

14. Ahmed N, Bestall JC, Ahmedzai SH, Payne SA, Clark D, Noble B (2004) Systematic review of the problems and issues of accessing specialist palliative care by patients, carers and health and social care professionals. Palliat Med 18:525-542. https://doi.org/10. 1191/0269216304pm921oa

15. Exley C, Field D, Jones L, Stokes T (2005) Palliative care in the community for cancer and end-stage cardiorespiratory disease: the views of patients, lay-carers and health care professionals. Palliat Med 19:76-83. https://doi.org/10.1191/0269216305pm973oa

16. Claessen SJJ, Francke AL, Echteld MA, Schweitzer BPM, Donker GA, Deliens L (2013a) GPs' recognition of death in the foreseeable future and diagnosis of a fatal condition: a national survey. BMC Fam Pract 14:104. https://doi.org/10.1186/1471-2296-14-104

17. Claessen SJJ, Francke AL, Engels Y, Deliens L (2013b) How do GPs identify a need for palliative care in their patients? An interview study. BMC Fam Pract 14:1-7. https://doi.org/10.1186/14712296-14-42

18. IKNL [Netherlands Comprehensive Cancer Center], Cijfers over kanker-Overleving kanker totaal [Statistics on cancer-survival all cancers] (2017) Available: http://www.cijfersoverkanker.nl/ selecties/overleving_kanker_totaal/img581754eaabd52. Accessed: 2-3-2017

19. Lunney JR, Lynn J, Foley DJ, Lipson S, Guralnik JM (2003) Patterns of functional decline at the end of life. JAMA 289:23872392

20. Murray SA, Kendall M, Boyd K, Sheikh A (2005) Illness trajectories and palliative care. BMJ 330:1007-1011. https://doi.org/10. 1136/bmj.330.7498.1007

21. Costantini M, Beccaro M, Higginson IJ (2008) Cancer trajectories at the end of life: is there an effect of age and gender? BMC Cancer 8:127. https://doi.org/10.1186/1471-2407-8-127

22. Eurostat Health Statistics (Causes of death) (2013) Available: http:// ec.europa.eu/eurostat/documents/2995521/7149996/3-03022016BP-EN.pdf/0bbc3389-8c0d-44a0-9b0c-2a0bff49f466. Accessed: 2-3-2017

23. Donker GA (2014) NIVEL primary care database - sentinel practices, 2014. Nivel, Utrecht Available: http:/www.nivel.nl/sites/ default/files/bestanden/Peilstations 2014 Engels.pdf

24. Dutch Government (2016) Wet bescherming persoonsgegevens [Dutch Personal Data Protection Act]. Available: http://wetten. overheid.nl/BWBR0011468/2016-01-01. Accessed: 2-3-2017

25. Bernards N, Mohammad NH, Creemers G, De Hingh IHJT, Van Laarhoven HW, Lemmens VEPP (2015) Ten weeks to live: a population-based study on treatment and survival of patients with metastatic pancreatic cancer in the south of the Netherlands. Acta Oncol 54:403-410. https://doi.org/10.3109/0284186X.2014. 953257

26. Abarshi E, Echteld MA, Van den Block L, Donker GA, Deliens L, Onwuteaka-Philipsen B (2010b) The oldest old and GP end-of-life care in the Dutch community: a nationwide study. Age Ageing 39: 716-722. https://doi.org/10.1093/ageing/afq097

27. Beernaert K, Deliens L, Pardon K, Van den Block L, Devroey D, Chambaere K, Cohen J (2015) What are physicians' reasons for not referring people with life-limiting illnesses to specialist palliative care services? A nationwide survey. PLoS One 10:e0137251. https://doi.org/10.1371/journal.pone.0137251

28. Statistics Netherlands (2014) CBS statline Ziekenhuisopnamen; geslacht, leeftijd en diagnose-indeling. [Hospital admissions; 
gender, age and diagnosis]. Via http://bit.ly/21ZLJnH. Accessed 23-2017

29. Bekelman JE, Halpern SD, Blankart CR, Bynum JP, Cohen J, Fowler R, Kaasa S, Kwietniewski L, Melberg HO, OnwuteakaPhilipsen B, Oosterveld-Vlug M, Pring A, Schreyögg J, Ulrich CM, Verne J, Wunsch H, Emanuel EJ (2016) Comparison of site of death, health care utilization, and hospital expenditures for patients dying with cancer in 7 developed countries. JAMA 315:272283. https://doi.org/10.1001/jama.2015.18603

30. De Korte-Verhoef MC, Pasman HR, Schweitzer BP, Francke AL, Onwuteaka-Philipsen BD, Deliens L (2014a) Reasons for hospitalization at the end of life; differences between cancer and non-cancer patients. Support Care Cancer 22:645-652. https://doi.org/10.1007/ s00520-013-2019-9

31. Barbera L, Paszat L, Qiu F (2008) End-of-life care in lung cancer patients in Ontario: aggressiveness of care in the population and a description of hospital admissions. J Pain Symptom Manag 35: 267-274. https://doi.org/10.1016/j.jpainsymman.2007.04.019

32. Kotajima F, Kobayashi K, Sakaguchi H, Nemoto M (2014) Lung cancer patients frequently visit the emergency room for cancerrelated and -unrelated issues. Mol Clin Oncol 2:322-326. https:// doi.org/10.3892/mco.2014.241

33. De Korte-Verhoef MC, Pasman HR, Schweitzer BP, Francke AL, Onwuteaka-Philipsen B, Deliens L (2014b) General practitioners' perspectives on the avoidability of hospitalisations at the end of life: a mixed-method study. Palliat Med 28:949-958. https://doi.org/10. $1177 / 0269216314528742$

34. Van den Block L, Pivodic L, Pardon K, Donker G, Miccinesi G, Moreels S, Vega Alonso T, Deliens L, Onwuteaka-Philipsen B
(2015) Transitions between health care settings in the final three months of life in four EU countries. Eur J Pub Health 25:569575. https://doi.org/10.1093/eurpub/ckv039

35. Cohen J, Houttekier D, Onwuteaka-Philipsen B, Miccinesi G, Addington-Hall J, Kaasa S, Bilsen J, Deliens L (2010) Which patients with cancer die at home? A study of six European countries using death certificate data. J Clin Oncol 28:2267-2272. https://doi. org/10.1200/JCO.2009.23.2850

36. Cohen J, Pivodic L, Miccinesi G, Onwuteaka-Philipsen BD, Naylor WA, Wilson DM, Loucka M, Csikos A, Pardon K, Van den Block L, Ruiz-Ramos M, Cardenas-Turanzas M, Rhee Y, Aubry R, Hunt K, Teno J, Houttekier D, Deliens L (2015) International study of the place of death of people with cancer: a population-level comparison of 14 countries across 4 continents using death certificate data. Br J Cancer 113:1397-1404. https://doi.org/10.1038/bjc.2015.312

37. Ploemacher J, Israëls AZ, Van der Laan DJ, De Bruin A (2013) Gestandaardiseerde ziekenhuissterfte daalt in de tijd [Standardised in-hospital mortality decreasing over time]. Ned Tijdschr Geneeskd 157:A5267

38. Lawson B, Burge FI, Critchley P, McIntyre P (2006) Factors associated with multiple transitions in care during the end of life following enrollment in a comprehensive palliative care program. BMC Palliat Care 5:4. https://doi.org/10.1186/1472-684X-5-4

39. Oosterink JJ, Oosterveld-Vlug MG, Glaudemans JJ, Willems DL, Onwuteaka-Philipsen BD (2016) Interprofessional communication between oncologic specialists and general practitioners on end-oflife issues needs improvement. Fam Pract 33:727-732. https://doi. org/10.1093/fampra/cmw064 